\title{
Integrated control of air and floor temperature in piglet houses: animal and engineering aspects
}

\author{
R Geers 1*, V Goedseels 1, G Parduyns 1, P Nijns 1, \\ $P$ Wouters 1 , L Bosschaerts 2 \\ 1 Laboratory of Agricultural Building Research, \\ Catholic University Leuven, de Croylaan 42, B-3030 Heverlee; \\ 2 Seghers Hybrid, Kapellebaan 45, B-9360 Buggenhout, Belgium
}

(Received 15 June 1989; accepted 22 December 1989)

\begin{abstract}
Summary - Despite the application of environmental engineering and control of air temperature within houses for intensively kept pigs, health and behavioural related problems are still observed which reduce the profit of the producer. Since these problems are influenced by the environment within a pen, an examination has been made of the possibilities of controlling floor temperature which must influence the micro-climate of the pig pen. Within these experiments, the object was to stabilize the lying behaviour of pigs, so that they preferred the same area for lying, ie not the dunging area, throughout the growing period. A series of experiments was set up with growing pigs (10$30 \mathrm{~kg}$ ) within climatic rooms, in which air temperature, air velocity and floor temperature were controlled. The air flow pattern was the same for all rooms and for all experiments. The lying behaviour, feed intake and growth rate were studied in relation to the above environmental parameters. The results show that the preferred floor temperature is dependent on pig age and on the nature of the floor itself. In order to stabilise the lying behaviour through the experimental period the temperature of the incoming air must also be taken into account. Parameters with respect to the thermoregulatory behaviour of pigs are put forward to be integrated within environmental control and engineering systems.
\end{abstract}

\section{floor temperature / piglets / control / behaviour / vision systems}

Résumé - Intégration de la température de l'air et du sol dans la régulation du climat des porcheries. Malgré des possibilités modernes de régulation des conditions climatiques dans les porcheries, on observe des problèmes en relation avec la santé et le comportement des animaux qui peuvent réduire le profit de l'engraisseur. Dans le but d'examiner la relation entre ces problèmes et la régulation des conditions climatiques, on a étudié limportance de la température du sol. Le but de cette étude était de stabiliser dans le temps le choix de la zone de confort thermique en un lieu différent de la zone des déjections. Une série d'expériences a été réalisée avec des porcelets de 10 à $30 \mathrm{~kg}$ de poids vif et dans des chambres où il a été possible de réguler la température de l'air et du sol, ainsi que la vitesse de l'air. Le comportement thermique, la consommation d'aliment et la croissance des animaux ont été examinés en relation avec ces paramètres du climat. Les résultats indiquent que la température optimale du sol dépend de l'âge du porcelet et du matériel du sol. La stabilisation du choix de la zone du confort thermique dans le temps dépend de la stabilisation du gradient thermique dans la loge. Ce gradient doit être obtenu par la température du sol et la vitesse de l'air en fonction de l'âge du porcelet.

température du sol / porcelets / régulation du climat / comportement

* Correspondence and reprints 


\section{INTRODUCTION}

In spite of environmental engineering and control facilities in modern pig houses, problems with respect to coughing, tail biting and pen fouling are observed within the so-called zone of thermal neutrality (Geers et al, 1988). These lead to a higher labour input and reduced growth rate and feed efficiency which reduce the profit of the farmer. These problems, probably related to the occurrence of stress (Dantzer and Mormède, 1979; Wiepkema, 1987), are complex and can only be understood by integrating knowledge of environmental engineering with that relating to the behavioural needs of the pig, eg pen fouling can be explained by a lack of structure in the environment, with interactions from stocking density (Randall et al, 1983; Fraser, 1985), that is, in the absence of suitable gradients in air temperature and air velocity, pigs will dung in their lying area as well as in the dunging area.

We focussed our attention on pen fouling and the following questions were posed: 1) Does a criterion based on the visual observation of behavioural thermoregulation (eg change of lying area, change of posture, lying apart or together) give sufficient information about the air and floor temperature needs of a growing piglet kept within a group? 2) When taking into account that criterion, do we need to engineer and control the pen environment on a gradient principle offering a possibility of choice, or on a concept of homogeneous control based on the assumed needs of an average animal?

\section{MATERIAL AND METHODS}

Six experiments were carried out. In each experiment, two groups of 6 female Belgian Landrace pigs were used. The growing period was from about $10 \mathrm{~kg}$ to about $30 \mathrm{~kg}$. Thermoregula- tory behaviour began to be quantified after about 1 wk of acclimatisation. A standardised commercial feed (dry pellets in a trough with 4 feeding places) and water were used ad libitum. Stocking density was $0.7 \mathrm{~m}^{2}$ /animal, taking into account total pen surface area.

Two climatic rooms, replicates of each other, were used. The air entering the house was conditioned by a water to air heat exchanger, which adjusted the air temperature. The floor was heated by means of a water to water heat exchanger. Both heat exchangers were controlled from 5 to $40^{\circ} \mathrm{C}$, but by separate digital controllers. The water flow through the floor was $500 \mathrm{l}$ $\mathrm{h}$. The temperature of the water irrigating the floor and of the air entering and leaving the room were measured with thermistors (accuracy $\pm 0.2^{\circ} \mathrm{C}$ ) every $10 \mathrm{~min}$ over $24 \mathrm{~h}$ and the mean values were calculated for presentation of results. According to Fourrier's Law, floor surface temperature was controlled by controlling the temperature of the water irragating the floor. It was easy to accurately measure water temperature, but not floor surface temperature taking into account the complex interactions of the heat exchange between the pig and the floor.

The ventilation rate was regulated by means of a fan and set at $200 \mathrm{~m}^{3} / \mathrm{h}$, which was the lower limit of fan capacity. The air inlet area was set manually to produce the desired air inlet speed $(1.5 \mathrm{~m} / \mathrm{s})$. Ventilation rate and air inlet area were standardised for all rooms and for all experiments in order to create an air velocity gradient reasonably constant both in space and time. In the target lying area, air velocity was measured with a heated-wire anemometer and found to be $0.2 \mathrm{~m} / \mathrm{s}$ when no animals were present. It was not possible to take this measurement when pigs were present. In a first set of $\mathbf{3}$ experiments the floor was constructed with plates of galvanized steel (4 mm thick). Under the plates, metal tubes were welded every $30 \mathrm{~cm}$. In these tubes a plastic tube (internal diameter $12 \mathrm{~mm}$ ) was fitted containing the running water. In a second set of experiments a concrete layer $(6 \mathrm{~cm}$ thick) was used. Under the concrete a plastic tube (internal diameter $12 \mathrm{~mm}$ ) was laid every $30 \mathrm{~cm}$, also containing the running water. In all cases sufficient thermal insulation $(5 \mathrm{~cm}$ styrodure) was available to restrict heat loss to the ground.

The room was dimly lit (75 lux) continuously throughout the experiment. A mathematical relationship was shown between the huddling behaviour of pigs and departure from the lower critical temperature (Boon, 1981). Huddling has the 
effect of increasing physical activity and causes heat losses to increase, because of the movement of the animals, which results in a lower feed efficiency (Mount, 1968). According to this author, optimal behaviour is when animals lie side by side in contact with each other, since in this case, heat losses and physical activities are minimised. Too high a temperature causes the pigs to lie separated from one another, which can be a waste of energy. Hence, parameters of thermoregulatory behaviour can be taken as a reference in order to evaluate environmental temperature (Geers et al, 1986).

From 8 pm until 8 am every $15 \mathrm{~min}$, a one minute video record was made of the lying area of the pen. This area was divided in 3 equal parts in order to facilitate quantification of the visual observations. The next day the tape was observed and the following data were collected: the number of sequences taken, the number of pigs per sub-area, their lying behaviour (side by side, apart or huddling).

The controller for air temperature (first step) and water temperature (second step) was set according to these observations, ie higher in the case of huddling, lower in the case of pigs lying apart. More specifically, when during periods of rest, animals were not lying side by side during a sequence of $1 \mathrm{~h}$ within the target being the sub-area having the lowest air velocity, first air temperature and then secondly, water temperature of the floor was changed in steps of $\pm 1^{\circ} \mathrm{C}$.

The animal's choice of the lying area could also be quantified by measuring the surface temperature of animals and floor with an infrared thermography system (Hughes Aircraft Company, USA). By calculating the proportion of pixels (a pixel is the smallest spatiallydigitized unit of an image) having a temperature value above a chosen threshold value, it was possible to quantify the floor areas occupied by pigs and the corresponding frequencies of occupancy. Within a week, each climatic room was observed over $2 \mathrm{~d}$ with this method. Again, the criterion as mentioned above was used to decide on a change of air and water temperature.

\section{RESULTS AND DISCUSSION}

Figure 1 shows for a metal floor and figure 2 for a concrete floor the values of air and floor temperature as a function of age of the animals (experimental days). These values are expressed as means calculated from independent measurements per pen and per experiment, taking into account parameters of behavioural thermoregulation of growing piglets (reference behaviour consists of pigs lying side by side in contact with each other).

There were significant differences between the metal and concrete floors as shown by the temperature of the water irrigating the floor. The mean values were $32.5 \pm 0.18{ }^{\circ} \mathrm{C}$ for metal and $38.0 \pm$ $0.18{ }^{\circ} \mathrm{C}$ for concrete $(P<0.001)$. With respect to the descending part of the curve, slopes were equal and statistically significant, ie in both cases $-0.826^{\circ} \mathrm{C} /$ day from day 1 to $22(P<0.001)$. But at the end of the experimental period the slope of the curve for the metal floor rose again. This means a temperature curve dependent on animal age as well as on the floor material used. With respect to the floor material used, a possible explanation is the difference between the heat capacity and heat conductivity of both floors. The metal floor has a lower heat capacity and a higher heat conductivity and these possibly allow more sensitive control of the water temperature to keep floor surface temperature according to the thermal needs of the piglets. As the experiment proceeded, there would be increased storage of heat with age in the concrete floor; this may explain why water temperature needed to be lowered throughout the experimental period. This will be investigated in further experiments.

No differences were observed with respect to the values of air temperature (entering and leaving). But a statistically significant slope was found when the temperature of the incoming air was related to pig age (metal - 0.214; concrete -0.203 ; $P<0.001)$.

When taking into account the thermoregulatory behaviour of growing piglets, it 


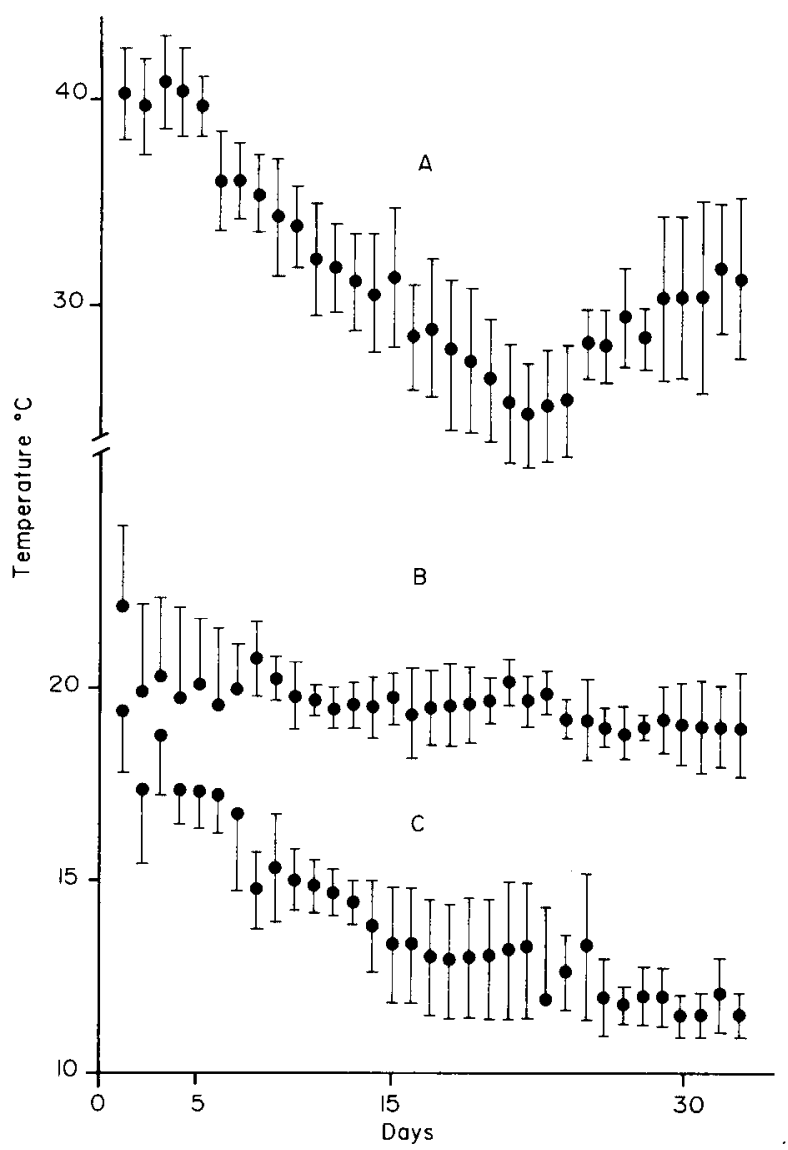

Fig 1. Metal floor: mean values with standard deviation of water temperature to the floor (A), pen air temperature $(B)$ and air inlet temperature $(C)$ over the experimental period.

was found that the same one-third of the total floor area was always used as the lying area and never the dunging area. This age-dependent preference shown by the pigs for a distinct combination of floor, air temperature and air velocity values shows that for a large lying area per pen $\left(4 \mathrm{~m}^{2}\right.$ for 6 piglets), a micro-climate gradient is sufficient to offer a possibility of choice to the piglets. This micro-climate gradient was the combination of a floor temperature gradient with an air velocity gradient.
In these experiments, overall mean values with respect to growth rate and feed conversion ratio were respectively $504 \pm$ $83 \mathrm{~g} / \mathrm{d}$ and $1.735 \pm 0.032$. No problems with respect to coughing, tail biting and dirty lying areas were observed. Since purebred animals as well as the same commercial food were used throughout all experiments, the small variability with respect to growth rate and food conversion ratio gives confidence in the reproducibility of the results with respect to environmental factors. 


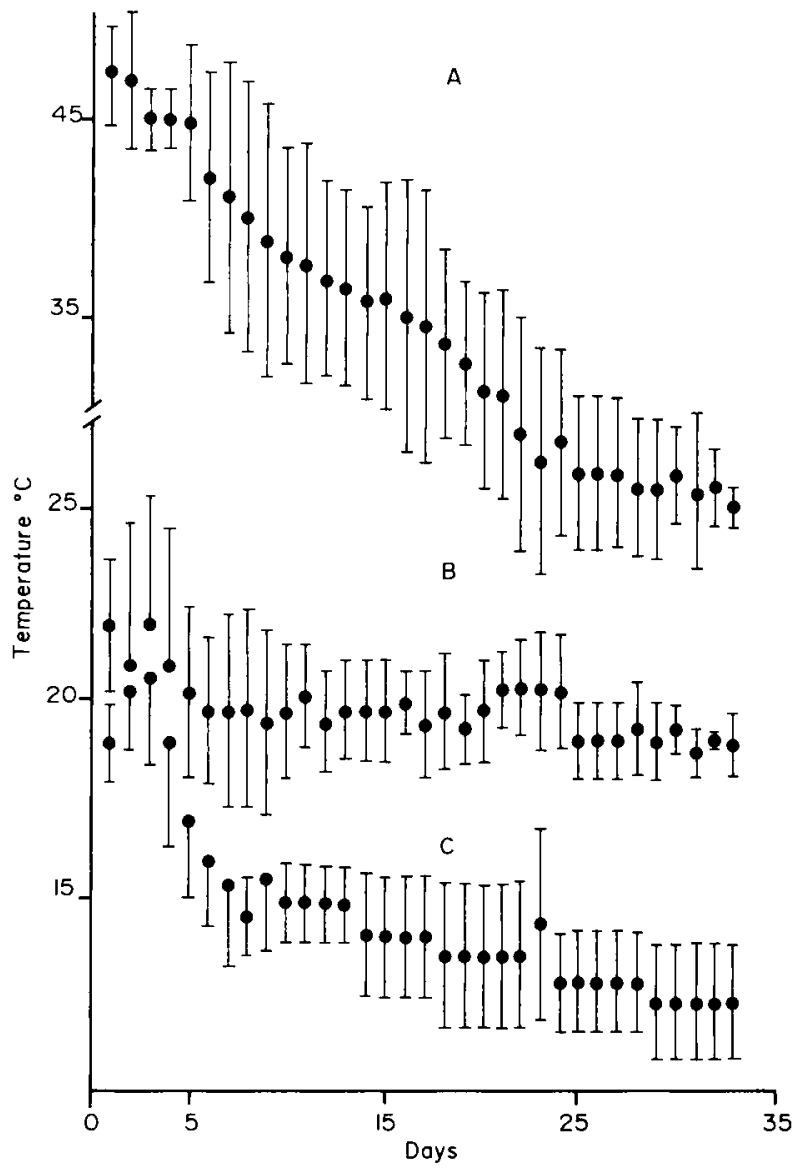

Fig 2. Concrete floor: mean values with standard deviation of water temperature to the floor (A), pen air temperature $(B)$ and air inlet temperature (C) over the experimental period.

\section{CONCLUSIONS}

The results show that the engineering and control of the house environment must be based on a structured heterogeneous concept offering a choice for the piglet's preferred micro-climate, which changes with age. This aim can be improved by controlling floor temperature together with air temperature, based on a quantifiable visual observation of the thermoregulatory behaviour of the animals.
In a house with growing pigs, small as well as large animals are present. Since the desired floor temperature depends on the age of the pigs (figs 1 and 2), heating and cooling of the circulating water is necessary, which can be achieved most economically by the use of a heat pump (Goedseels et al, 1988).

The engineering of a stabilized air temperature across a pig house by means of controlling the air flow pattern, through 
changing outside temperatures, can be based on the control of the Archimedes' number of the incoming air (Randall and Battams, 1979). In order to provide the desired stabilised temperature difference between lying and dunging area within each pen within a traditional pig house, air inlets must be placed symmetrically and air inlet areas controlled automatically in order to cope with the frequently changing outside environment (Geers et al, 1984). However, the problem can be simplified by adjusting the temperature of the incoming air to a constant value and by providing each pen of the house with an individual air inlet as in the experiment reported here. In this case air velocity at the inlet can be calculated according to Randall and Battams (1979) in order to create a jet stream across the dunging area, but avoiding air turbulence in the pen. Moreover, it is also possible to work at minimal ventilation capacity.

The principle of controlling the environment by means of quantifying the behaviour of the pigs, as developed in laboratory conditions (Geers et al, 1986), can be integrated in intelligent sensor systems (Goedseels et al, 1988). The system described needs further evaluation under practical farming conditions.

\section{ACKNOWLEDGMENTS}

Mr Bloemen (Nooyen) supplied the floors. The Research Council of the Catholic University (Leuven) and the Fund for Collective and Fundamental Research (Belgium) funded the climatic rooms and the data measuring and acquisition equipment. R Geers was supported by the National Fund for Scientific Research (Belgium).

\section{REFERENCES}

Boon CR (1981) The effect of departures from lower critical temperature on the group postural behaviour of pigs. Anim Prod 33, 71-79

Dantzer R, Mormède P (1979) Le Stress en Elevage intensif. Masson, Paris, 150

Fraser D (1985) Selection of bedded and unbedded areas by pigs in relation to environmental temperature and behaviour. Appl Anim Behav Sci 14, 117-126

Geers R, Randall JM, Battams VA, Huybrechts $W$ (1984) Providing environmental control in all-in all-out rooms for finishing pigs. Farm Buildings \& Engineering 1, 27-30

Geers R, Goedseels V, Parduyns G, Vercruysse $G$ (1986) The group postural behaviour of growing pigs in relation to air velocity, air and floor temperatures. Appl Anim Behav Sci 16, 353-362

Geers R, Vranken E, Goedseels V, Berckmans D, Maes F (1988) Air temperature related behavioural problems and mortality rate of pigs. 3rd Int/ Livestock Environment Symp, Toronto, April 25-27, ASAE Publication 1-88, 343349

Goedseels V, Geers R, Berckmans D (1988) Optimization of pig production processes using principles of biosensors combined with floor materials conditioned by heat pumps. 2nd int Conf on Rational Use of Local Energy Sources and Electrical Thermal Consumption in Agriculture, Balatonfüred, May 16-22 (in press)

Goedseels V, Geers R, Berckmans D, Van der Stuyft $E$ (1988) The combination of polymer materials with a new sensor concept in relation to the use of heat pumps and solar energy in order to optimize the pig production process. AG ENG 88, Paris (abstr)

Mount LE (1968) The Climatic Physiology of the Pig. Arnold, London, 271 
Randall JM, Battams VA (1979) Stability criteria of airflow patterns in livestock buildings. $J$ Agri Eng Res 24, 361-374

Randall JM, Armsby AW, Sharp JR (1983) Cooling gradients across pens in finishing piggery. J Agric Eng Res 28, 247-259
Wiepkema PR (1987) Behavioural physiological aspects of energy metabolism in vertebrates. In: Energy Metabolism and Production as influenced by Environmental Factors (Van der Hel W, Henken AM, ed) Landbouw Universiteit Wageningen, 49-58 